International Journal of Child, Youth and Family Studies (2017) 8(1): 97-111

DOI: http://dx.doi.org/10.18357/ijcyfs81201716855

\title{
YOUNG ADULTS' EXPERIENCES WITH NEAR-INJURY SITUATIONS: A CRITICAL INCIDENT STUDY IN SWEDEN
}

\author{
Richard Allan Dale, Annette Sverker, Marie Hasselberg, \\ Gunnel Östlund, and Gunnel Hensing
}

\begin{abstract}
As injuries are the main health threat for young adults (18-29 years) in industrial countries, a better understanding of injury risk is needed for this population. Using the Critical Incident Technique, this study explores how young people experience situations that have the potential to cause physical injury (i.e., near-injury situations). Clearly, understanding how and why nearinjury situations arise can be used to develop strategies to help prevent severe injury. Content analysis was used to categorize the characteristics of the experiences into unexpected risk in ordinary tasks, duty first, and price for learning. Young adults' exposures to new or unusual environmental conditions, especially in unexpected risk in ordinary tasks, should be considered when planning injury prevention strategies. A combination of individual, social, and contextual demands and expectations was identified in both work- and sportsrelated experiences with near-injury situations. The price for learning, which arises from the added risk involved in learning situations, is another condition that was identified and requires further attention. The Critical Incident Technique proved to be a useful method for identifying near-injury situations that might otherwise have been difficult to recall. Young adults' efforts to display their ability to handle difficult situations at work and in their everyday lives was identified as a major contributor to near-injury situations.
\end{abstract}

Keywords: young adults, lived experiences, near-injury, Critical Incident Technique, qualitative study

Richard Allan Dale PhD is Public Health Manager in the city of Gothenburg and Lecturer in the Section of Epidemiology and Social Medicine, Sahlgrenska Academy, University of Gothenburg, Box 100, S-405 30, Gothenburg, Sweden. Email: allan.dale@afh.goteborg.se

Annette Sverker PhD (the corresponding author) is a lecturer in Social Medicine in both the Department of Medical and Health Sciences (Department of Activity and Health; Department of Rehabilitation Medicine) and the Department of Social and Welfare Studies (Social Work division) at Linköping University, Linköping, Sweden. The address for correspondence is Rehabilitation Section NSC, County Council of Östergötland, 58185 Linköping, Sweden. Email: annette.sverker@liu.se

Marie Hasselberg is Associate Professor of Epidemiology in the Department of Public Health Sciences, Karolinska Institutet, Sweden. Email: Marie.Hasselberg@ki.se

Gunnel Östlund is Associate Professor in the School of Health and Social Welfare, Mälardalen University, S63105 Eskilstuna, Sweden. Email: gunnel.ostlund@mdh.se

Gunnel Hensing $\mathrm{PhD}$ is Professor of Social Medicine in the Section for Epidemiology and Social Medicine, Sahlgrenska Academy, University of Gothenburg, Box 100, S-405 30, Gothenburg, Sweden. Email: gunnel.hensing@gu.se 
Worldwide, injuries are the leading cause of premature death in young people (Connor \& Casswell, 2009; Hasselberg, Laflamme, \& Weitoft, 2001; Koehoorn, Breslin, \& Xu, 2008; Mulye et al., 2009; Salminen, 2004; WISQARS, 2010). However, fatal injuries represent only a small proportion of total injuries. Annually, 7.5 million young people (15-24 years) are treated for an injury in European Union hospitals (European Association for Injury Prevention and Safety Promotion, 2013), mainly due to events that occurred at home or when participating in leisure or sports activities. Hospital data from the European countries show that nonfatal injuries are the leading cause of permanent disability and reduction in quality of life among those aged 15 to 24 (European Association for Injury Prevention and Safety Promotion, 2013). These injuries can result in long-lasting health-related conditions that may hinder the injured from reaching their full potential while also imposing heavy societal costs for treatment and other kinds of support (European Association for Injury Prevention and Safety Promotion, 2013). Studies specifically examining non-fatal injuries that occur during the time when young people emerge into adulthood are not readily available, as relevant studies, including reports from the World Health Organization, either analyse data from young adults (18-29 years) along with data from adolescents, or collapse the young adult into data gathered on the general adult population. This lack of consistency makes it difficult to observe the injury risk for adolescents, reducing the possibility that the data can guide the development of targeted injury prevention programs for this age group.

Emerging adulthood (18-29 years) is now an established concept describing the period between late adolescence and adulthood (Arnett, 2007; Arnett, Zukauskiene, \& Sugimura, 2014; Douglass, 2007; Walther, 2006). The concept has been widely used in developmental psychology in characterizing the life of this age group and has been described by Arnett (2007) as "the most heterogeneous period of the life course because it is the least structured". During this period of life most people in the northern part of Europe leave their parents' homes and may lose parental financial support (Iacovou, 2010; le Blanc \& Wolff, 2006). Emerging adulthood entails developmental challenges: it is a period of life when people form their identities while encountering many types of new situations and environments. It may also carry an increased risk of injury.

Another factor that may increase the risk of injury is a propensity for risk-taking behaviours. It has been suggested that young adults who engage in risk-taking behaviours generally underestimate their vulnerability (Benthin, Slovic, \& Severson, 1993; Kontos, 2004; Sjoberg, 2000), feel little fear of serious consequences (Benthin et al., 1993; Sjöberg, 2000; Slovic, Finucane, Peters, \& MacGregor, 2004), perceive that they have more control over risky situations than they actually have (Benthin et al., 1993; Kontos, 2004; Sjoberg, 2000), and become involved in risky situations due to reward responsiveness associated to peer influence or seeking group acceptance (Reniers et al., 2017; Slovic et al., 2004; Wild, Flisher, Bhama, \& Lombard, 2004). Research focusing on young adults' injury risk is important for public health policy, especially when it comes to injury prevention related to high-injury risk and the high societal costs of injuries at this age (loss of earnings, loss of productivity, as well as medical and other costs), given that severe injuries can be predictable and preventable (European Association for Injury Prevention and Safety Promotion, 2014). 
One approach to gaining a better understanding and deeper knowledge of the circumstances surrounding injury events has been to study injury-risk situations that did not lead to actual injury — that is, near-injury situations (Alamgir, Yu, Gorman, Ngan, \& Guzman, 2009; Jones, Kirchsteiger, \& Bjerge, 1999; Wagner, Capezuti, \& Ouslander, 2006; Wright \& van der Schaaf, 2004). Near-injury situations have mainly been studied in the context of occupational safety (Alamgir et al., 2009; Jones et al., 1999; Wagner et al., 2006; Wright \& van der Schaaf, 2004) based on the assumption that the causal pathways are the same for nearinjury events as for events that result in severe injuries, the so-called common cause hypothesis (Heinrich, 1931). If that hypothesis is accepted, injury prevention should rely on information from near-injury events rather than just actual injuries. We have adapted this hypothesis here; as far as we know, this is the first study to investigate how near-injury situations can be used to understand actual injury situations and ultimately to develop injury prevention strategies for young adults, an especially vulnerable age group. There are several public health incentives for seeking in-depth knowledge based on young adults' own experiences. Therefore, the aim of this study is to explore, describe, and categorize circumstances associated with young adults' experiences of near-injury situations.

\section{Methods}

\section{Design}

The Critical Incident Technique (CIT; Flanagan, 1954) was chosen to be the most suitable method for data collection for this exploratory study. CIT is a systematic, inductive, and flexible research method for collecting subjective experiences (Flanagan, 1954; Byrne, 2001; Bradley, 1992). Previous studies have shown that CIT helps interviewees recall present and former lived experiences in a clear and detailed way (Hensing, Sverker, \& Leijon, 2007; Suvivou, Tossavainen, \& Kontula, 2007; Sverker, Hensing, \& Hallert, 2005). Although CIT has been used in some specific hazardous fields, this is the first time, as far as we know, that it has been used to explore the common daily situations that give rise to the majority of nearinjury situations. Data were collected through semi-structured interviews, which enabled the participants to describe detailed experiences of the near-injury situations they had encountered. The study was approved by the Ethics Committee at the University of Gothenburg, Sweden (Approval No 626-06).

\section{Participants}

To ensure a broad variation of near-injury situations, a random sample from three sources was used: a local register of university students in a semiurban municipality, a register of employees in a food factory in a rural area, and injured people attending an emergency room at one of the local hospitals between January 2008 and June 2009. The study took place in the Skaraborg region, a mainly agricultural and manufacturing area in Sweden. 
International Journal of Child, Youth and Family Studies (2017) 8(1): 97-111

Table 1 Summary of characteristics of participating young adults, Sweden 2008-2010

\begin{tabular}{lcccc}
\hline Characteristic & $\begin{array}{c}\text { Female } \\
18-20\end{array}$ & $\begin{array}{c}\text { Female } \\
21-24\end{array}$ & $\begin{array}{c}\text { Male } \\
18-20\end{array}$ & $\begin{array}{c}\text { Male } \\
21-24\end{array}$ \\
\hline Number & 8 & 3 & 5 & 3 \\
Living alone & 0 & 0 & 0 & 1 \\
Living with someone & 8 & 3 & 5 & 2 \\
Living in the city & & & & \\
Living outside the city & 4 & 1 & 1 & 0 \\
Studying & & 0 & 2 & 2 \\
Working & 6 & 2 & 3 & 1 \\
Both studying and working & 1 & 0 & 0 & 0 \\
Not studying or working & 1 & 1 & 0 & 0 \\
\hline
\end{tabular}

From the register of students and the register of employees, a random sample was chosen to receive written information about the study. As well, written information was sent to injured people who were willing to participate in the study when asked by a nurse at the emergency room. After two weeks, personal telephone contact was made and the time and place for the interview was decided with the participants' input. During this interview, the participants were again fully informed about the study, and told that their participation was voluntary and they could withdraw at any time. Those who declined to participate did so mainly due to lack of interest or time. Twenty people were interviewed (see Table 1for a summary of the characteristics of the participants). One interview was excluded since no near-injury situation was described.

\section{Data collection}

All interviews opened with questions about situations in which participants had been physically injured. Next, they were asked to describe experiences when they came close to but escaped being physically injured. The interviewees were then asked to report at least two specific injury situations in great detail and to describe as many subjective experiences of the near-injury situations as possible. Follow-up questions were asked to encourage the interviewee to describe each situation in more detail and how the interviewee managed the situation. The interviews lasted between 45 and 60 minutes and were digitally recorded and transcribed verbatim. All data were collected between March 2008 and June 2010.

\section{Data analysis}

The analysis was guided by the manifest content analysis approach (Graneheim \& Lundman, 2004). We read the transcribed interviews several times to become familiar with the data and to obtain a sense of the whole. Nonspecific or incomplete experiences (when the interviewee could not provide detailed information of a specific situation) were excluded from the analysis. The data were organized into categories and subcategories. To ensure that the classification was as free from bias as possible and could be replicated, we identified and categorized the near-injury situations in the following way: 
1. The content of each subjective experience was scrutinized line-by-line by two of the authors, and meaning units were identified, condensed, and codified with keywords.

2. The keywords were compared and sorted into tentative categories and subcategories for each theme.

3. The findings were then discussed by all the authors. A continuous movement back and forth between the transcribed material and the tentative findings was done during the analytical process and when forming the results.

4. The categories were compared and revised until the final classification was determined.

\section{Results}

The young adults in this study described a wide range of near-injury situations in great detail. From these descriptions three main types of near-injury situation were identified: unexpected risk in ordinary tasks, duty first, and price for learning (see Table 2).

\section{Unexpected risk in ordinary tasks}

This category included near-injury situations that happened suddenly while the participant was performing an everyday life task, such as walking, running, jumping, dancing, riding a bike, or driving a car. The participants described situations in which they suddenly found themselves in a risk-zone because they hadn't recognized how dangerous the situation had become. Two subcategories were identified: "Sudden unfamiliar situations", and "Lack of concentration”.

Most of the near-injury situations happened when what seemed like a familiar situation suddenly became unfamiliar. Many of these sudden unfamiliar situations were described as being due to bad weather conditions while walking, driving a car, or riding a bike, and often included a combination of several negative external factors such as darkness, rain, wet roads, and another vehicle behaving in an unfamiliar way (Quote I, Table 2). Other near-injury situations featured unexpected encounters with wild animals when driving a car on rural roads, or other people's risky behaviour or negligence.

In the subcategory "lack of concentration", the second kind of unexpected risk encountered while engaged in ordinary tasks, the participants described finding themselves in a risky situation because they were not attentive (Quote II, Table 2). For example, one participant related an experience of nearly being hit by a car while chasing a friend during a snowball fight. In another case, a participant was talking with friends while trying to cross a street during rush hour. 
International Journal of Child, Youth and Family Studies (2017) 8(1): 97-111

Table 2 Characteristics of near-injury situations experienced by emerging adults exemplified by quotations from individual interviews, Sweden 2008-2010

\begin{tabular}{|c|c|c|}
\hline $\begin{array}{l}\text { Near-injury } \\
\text { situation }\end{array}$ & Subcategory & Quotes from individual interviews \\
\hline \multirow[t]{2}{*}{$\begin{array}{l}\text { Unexpected } \\
\text { risk in } \\
\text { ordinary tasks } \\
(42)\end{array}$} & $\begin{array}{l}\text { Sudden } \\
\text { unfamiliar } \\
\text { situations } \\
\text { (40) }\end{array}$ & $\begin{array}{l}\text { I. It was pretty early in the morning when I left my work } \\
\text { to go home ... It was dark and raining when I was driving } \\
\text { my small car on the highway, and suddenly a big truck } \\
\text { was behind me ... The driver forced me to go faster with } \\
\text { his lights and by driving very close to me ... and suddenly } \\
\text { there was a lot of water in the way, so I lost control of my } \\
\text { car and drove off the road. (adult aged 22) }\end{array}$ \\
\hline & $\begin{array}{l}\text { Lack of } \\
\text { concentration } \\
\text { (2) }\end{array}$ & $\begin{array}{l}\text { II. Friday after school ... I was crossing a street with two } \\
\text { friends. We used the crosswalk. There were a lot of } \\
\text { people and cars. We were talking, and while we were in } \\
\text { the middle of the street, a car came very fast from the left } \\
\text { side. The driver stopped very close to us. (adult aged 19) }\end{array}$ \\
\hline \multirow[t]{2}{*}{$\begin{array}{l}\text { Duty first } \\
\text { (16) }\end{array}$} & $\begin{array}{l}\text { Solving } \\
\text { work-related } \\
\text { problems } \\
\text { (13) }\end{array}$ & $\begin{array}{l}\text { III. I was passing nearby and saw that a box was stuck in } \\
\text { the machine, so I stopped the machine, went in alone, and } \\
\text { when I took away the box another box fell down a few } \\
\text { centimetres from me. (adult aged 22) }\end{array}$ \\
\hline & $\begin{array}{l}\text { Managing } \\
\text { sport duels } \\
\text { (3) }\end{array}$ & $\begin{array}{l}\text { IV. It was an important football match for us ... The ball } \\
\text { was coming in my direction and a girl from the other team } \\
\text { also wanted the ball, so I jumped and turned my body in } \\
\text { the air against the other girl ... I wanted to prove to the } \\
\text { others on my team that I was determined to win the game. } \\
\text { (adult aged 18) }\end{array}$ \\
\hline \multirow[t]{2}{*}{$\begin{array}{l}\text { Price for } \\
\text { learning } \\
(12)\end{array}$} & $\begin{array}{l}\text { Trying new } \\
\text { skills } \\
\text { (3) }\end{array}$ & $\begin{array}{l}\text { V. During my first diving lesson I had to go down five } \\
\text { metres deep and take off my mask, and instead of doing } \\
\text { it slowly I pulled my mask straight off and lots of water } \\
\text { came in - scary - and I more or less panicked and } \\
\text { began to swim upwards, and the dive master was behind } \\
\text { me and grabbed me and put the regulator in my mouth so } \\
\text { I could breathe. After that he took me up to the surface. } \\
\text { (adult aged 24) }\end{array}$ \\
\hline & $\begin{array}{l}\text { Improving } \\
\text { skills } \\
\text { (9) }\end{array}$ & $\begin{array}{l}\text { VI. It was practice. I fell backwards. I had pretty good } \\
\text { speed and I lost balance and fell backwards, so I scraped } \\
\text { up my back a little and got a mark here. (adult aged 20) }\end{array}$ \\
\hline
\end{tabular}

\section{Duty first}

The near-injury situations identified as “duty first” happened while performing under pressure. These situations occurred either at work or while engaged in team sports, when the participants wanted to live up to their own expectations or what they perceived to be other people's expectations. Often in describing these situations participants talked about feeling pressure to complete a work task as fast as possible and of being unsure when and if they were 
allowed to ask for help. This time-related pressure to perform well was also described as leading to stress-related failures and increased clumsiness.

Interviewees who experienced near-injury in work-related duty-first situations recalled experiencing stress due to tight work schedules, lack of staff, or feeling that it was their responsibility to solve the situation without guidance. These self-generated pressures led to situations where they did things on their own initiative like using unfamiliar equipment such as a truck or trolley. For example, one participant described a near-injury situation when, on his own initiative, he decided to fix a problem involving a large machine. The participant was almost hit by a falling object even though he thought he had played it safe by turning off the electricity (Quote III, Table 2). Another example was provided by an interviewee who, as a new employee at a home for the elderly, was almost injured when attempting to lift a patient without help from other workers. Clearly, both these young people required more supervision and training.

Sports-related duty-first near-injury situations typically involved team sports, especially hockey and football. During the sports-related near-injury events, participants felt they had to prove to their teammates that they were tough, so they took chances that put them at risk (Quote IV, Table 2). Participants were even more likely to put themselves at risk if they had a leading role in a team. These self-generated performance-based expectations put extra pressure on the participants, placing them at greater risk of injury.

\section{Price for learning}

The third identified type of near-injury situation was labelled "price for learning" because it includes situations that happened when the participant was trying to learn something new or to improve a specific skill. In many of the examples, the participant was trying an activity for the first time, such as diving into a swimming pool, jumping on a trampoline, or learning deep diving techniques (Quote V, Table 2). For some participants, price-for-learning situations occurred when the participant had some experience with the activity but was trying to improve through practice. These near-injury situations sometimes happened when the participants left their “safe zones” in order to improve skills; for example, learning new skating moves (Quote VI, Table 2).

\section{Discussion}

An inductive analysis of the collected qualitative data was done to learn more about the conditions behind young adults' near-injury situations in everyday life. The three main categories that emerged from our analysis will be discussed individually here, along with methodological considerations.

\section{Unexpected risk in ordinary tasks}

Overall we found that sudden unfamiliar situations were the most common near-injury situations experienced by the young adults. Exposure to new environmental conditions put the participants at risk due to their lack of experience, which also might have influenced their subjective interpretations of hazardous situations. Young drivers' greater tendency than older 
drivers to engage in risky driving has been explained by their lack of experience, and consequent lack of a holistic understanding of the risks (Borowsky, Shinar, \& Oron-Gilad, 2010). While studies have found that some people, regardless of age, will take an active decision to involve themselves in a risky situation due to their self-perceived ability to control the situation (DeJoy, 1989), it may be important to keep in mind that for young adults especially, engagement in risky situations might be associated with their incomplete appreciation of the level of risk (Johnson, McCaul, \& Klein, 2002).

Earlier studies have suggested that active decision-making based on the perception both of the level of risk and of potential benefits is an important factor behind people's involvement in risky situations (Benthin et al., 1993; Jones et al., 1999; Sjoberg, 2000; Slovic et al., 2004). According to this line of research, perception of risk is based on a complex interaction between rational and emotional systems - between what people think about the situation and how they feel. This line of reasoning also suggests that states of mind are associated with certain situations and activities (Benthin et al., 1993). Thus when young adults move from being passengers to being drivers, they might underestimate the complexity of the activity since they are used to being a passenger. The inexperienced driver still has the responsibility to be safe, but those who provide young drivers with their first-time opportunities to drive must keep in mind the risks that come with novice driving.

Previous research suggests that young adults' perception of benefits, such as social prestige in a group or having fun, has more influence on their behaviour than their perception of risks (Parsons, Siegel, \& Cousins, 1997). Our sample has reported priorities not found in previous research, and seems to point to the need for a complementary perspective in safety and preventive research. Such a perspective would focus on processes of adaptation to situations and social contexts that relate to a wish to belong, do well, develop, and perform as a mature person. We do not mean that the "having fun" driver is unimportant, but that the attention it has been given might have overshadowed the more mature ambitions of young adults. The age of the population under study might also help to explain this effect.

We have already mentioned that a further refinement of categories and their conceptual affiliations would be valuable. However, we also suggest that our findings be taken further by the development of a questionnaire for an epidemiological survey to assess the prevalence and distribution of these experiences over gender, socioeconomic background, educational level, and other relevant factors. Furthermore we believe that our data can provide a foundation for the future development of scales that measure fine-tuned aspects of each of the categories, such as clusters of subcategories, grades of intensity of a certain experience, and emotional associations of an experience. Our findings open avenues for further research and the associated development of new knowledge concerning both near-injury situations among young adults and the best focus for safety and preventive work.

\section{Duty first}

Interestingly, we found that young adults were influenced by their surroundings more than we expected. For example, when performing tasks in the company of other people, the 
participants were less observant of hazardous situations. Trying to live up to others' expectations emerged as an important contributing factor to near-injury, seemingly because the desire to perform well in the eyes of others trumped any assessment of hazards. This desire to meet expectations and perform well has seldom been discussed as a possible contributing cause of injury. Instead, research often focuses on such patently negative factors as taking too many risks, and operating in a risky physical environment (Haddon, 1980; Peek-Asa \& Zwerling, 2003; Runyan \& Zakocs, 2000). We therefore suggest that future research continue our line of inquiry to refine categories and confirm their demarcations.

There is also a need to further define the conceptual classification at more abstract or structural levels; in other words, to elucidate how the categories can be understood from different disciplinary perspectives and whether the different categories can be seen as representative of the individual, group, or even societal level. The classification of the categories should contribute to better understanding how preventive interventions can be designed. Qualitative categories are often based, as in our study, on experiences and thus are concrete. However, research needs theoretical definitions to move the perspective from the concrete and experience-based to the more abstract and theoretical in order to develop and test hypotheses in other populations and contexts. More specifically, it is important to know whether the desire to perform well or meet expectations is best understood as individual psychology, social psychology, or microsociology in order to pursue theoretically wellgrounded suggestions for safety and preventive work. We abstain at present from considering how the question of disciplinary understanding could be settled; we do not think that our data is appropriate for this, and the issue can only be resolved by future studies.

Another interesting finding of this study was that psychosocial working conditions such as stress and time pressure were identified as potential injury-risk factors, especially when we consider the fact that young adults often work in insecure and precarious job situations. Earlier research has shown that temporary contracts are potential injury-risk factors for young workers (Salminen, 2004). Under temporary contracts, young workers may encounter situations that increase potential risks in line with our findings; situations that entail performing under pressure, adapting to social expectations, or trying to impress others.

The willingness to adapt to other people's expectations and the desire to impress others regardless of performance pressure or social expectations naturally differs among individuals. However, young adults are particularly vulnerable in this respect, since they are at an age of transformation and identity formation and in need of economic self-sufficiency. From a preventive perspective, more research is needed on how psychosocial, organizational, and employment factors affect young employees' injury risks at work, and to advance knowledge regarding young employees’ experiences with their work environment.

Further, the adjustment to duties could be viewed as a safety risk for young adults, and could be understood as a knowledge gap in safety-risk prevention research. The pressure to hold a job can impact safety negatively if it results in safety arrangements being set aside. Similarly, young adults place themselves in risky positions when, in an attempt not to be perceived as overdependent or unqualified, they avoid asking for needed guidance and help. 
These considerations support the findings of previous studies focusing on safe work environments for adolescents and young adults that have recommended taking into account the characteristics of the young workers, not only the characteristics of the workplace and their assignments (Runyan et al., 2000; Salminen, 2004).

Wanting to be seen as competent and as performing well for others were also factors in potential injury-risk situations in sports duels, common in football, handball, and many of the other team sports participants mentioned. The presence of internal (psychological) and external (social) pressures was evident in the young adults' descriptions of sports-related risky behaviours. It is known that sport injuries are common in young people. (Darrow, Collins, Yard, \& Comstock, 2009; Steffen, Myklebust, Olsen, Holme, \& Bahr 2008). Our findings about the pressures that our participants described may help to explain these injuries.

Some participants mentioned that sports coaches challenged competitors to show their desire to win and to be seen as an asset to their teams. Earlier studies have found that the psychological interplay between a coach and players is associated with the players' performance (Balaguer, Duda, Atienza, \& Mayo, 2002; Barnett, Smith, \& Smoll, 1992). Thus, pressure to perform is not exclusive to work-related experiences. Since many work positions are conceived of as requiring teamwork, it is possible that the interplay between a supervisor and young workers is similar to that between a coach and players; the desire to meet or exceed expectations (e.g., win a game, deliver a product, or keep a position on the team) might then put young workers and young players alike at higher risk of injury.

According to the young adults in our study, supervision and guidance are protective factors; they expressed a desire for supervision when performing new work tasks and when learning new leisure activities. These findings fit with earlier studies that have recommended close supervision to reduce the impact of injury-risk situations on young workers (Salminen, 2004; Wegman \& Davis, 1999). Given our findings and those of previous researchers, injuries to inexperienced workers could be reduced if employers and work managers took care to emphasize job safety and to maintain an open climate where inexperienced workers are encouraged to ask for help.

\section{Price for learning}

We also found that learning new leisure activities or improving sports skills through independent practice are injury-risk factors for young adults. Leisure activities (e.g., improving skateboard techniques) often involve some kind of risk. However, reflecting about possible near-injury situations might help young adults (and people in general) to better anticipate risk. Instructors must take care to provide information on safety when needed to keep the student safe in particular activities (e.g., learning how to dive). The presence of another person and, in particular, the role and behaviour of this person before and during an injury-risk situation, could be an interesting focus of future studies that aim to understand risks and opportunities for prevention in both work- and sports-related injury-risk situations for young adults. 


\section{Methodological considerations}

At first, most of our interviewees had difficulty identifying near-injury situations, but they eventually provided detailed and colourful descriptions of minor as well as major nearinjury situations. CIT made it possible to collect a wide range of subjective experiences, which provided rich material for the analysis of the young adults' experience with near-injury situations in everyday life. The variety and richness in detail of the collected near-injury situations illustrates the importance of collecting lived experiences of near-injury situations, a strategy that previous research ignores. Although the use of a data collection methodology based on interviews might be vulnerable to recall difficulties and recall errors, retrospective methods are nonetheless well suited to collecting subjective experiences.

Moreover, the time elapsed since the experience might be less of a consideration since a perceived risk of injury was involved: one's recall of fearful situations is often more accurate than that of ordinary events (Flanagan, 1954). Given how well CIT worked for us, we now believe that CIT could also be used when developing and evaluating preventive strategies based on self-reported risky situations.

\section{Conclusion}

This study shows that CIT is well-suited for collecting information about near-injury situations in young adults' everyday lives. We found that young adults' lived experiences of near-injury situations were associated with performance pressure more distinctly than expected given the findings from earlier studies.

The young adults who participated in this study wanted to adapt, to keep out of trouble, and to perform well, possibly in order to keep their jobs or to win a sports competition. Their efforts to display their ability to handle difficult situations at work and in their everyday lives was identified as an important contributor to near-injury situations. These results can be used when planning and designing injury prevention strategies. Executives at work and in sports should be aware of young adults' willingness to adapt as a factor that might lead them to go beyond their capacity, placing them at higher risk of injury. The early stages of independence and adult life are demanding in multiple ways, and carry new physical hazards that may result in near-injury situations as categorized in this study. More studies are needed to refine the categories we identified and to assess quantitatively their prevalence and association to other risk factors.

\section{Acknowledgements}

This study was supported by the Swedish Civil Contingencies Agency and the Public Health Office in the Region of Västra Götaland. 
International Journal of Child, Youth and Family Studies (2017) 8(1): 97-111

\section{References}

Alamgir, H., Yu, S., Gorman, E., Ngan, K., \& Guzman, J. (2009). Near miss and minor occupational injury: Does it share a common causal pathway with major injury? American Journal of Industrial Medicine, 52(1), 69-75.

Arnett, J. J. (2007). Emerging adulthood: What is it, and what is it good for? Child Development Perspectives, 1(2), 68-73.

Arnett, J. J., Zukauskiene, R., \& Sugimura, K. (2014). The new life stage of emerging adulthood at ages 18-29 years: Implications for mental health. Lancet Psychiatry, 1(7),569-576. doi:10.1016/S2215-0366(14)00080-7

Balaguer, I., Duda, J. L., Atienza, L., \& Mayo, C. (2002). Situational and dispositional goals as predictors of perceptions of individual and team improvement, satisfaction and coach ratings among elite female handball teams. Psychology of Sport and Exercise, 3(4), 293308.

Barnett, N., Smith, R. L., \& Smoll, F. (1992). Effects of enhancing coach-athlete relationships on youth sport attrition. The Sport Psychologist, 6, 111-127.

Benthin, A., Slovic, P., \& Severson, H. (1993). A psychometric study of adolescent risk perception. Journal of Adolescence, 16(2), 153-168.

Borowsky, A., Shinar, D., \& Oron-Gilad, T. (2010). Age, skill, and hazard perception in driving. Accident Analysis \& Prevention, 42(4), 1240-1249.

Bradley, C. P. (1992). Turning anecdotes into data - The critical incident technique. Family Practice, 9(1), 98-103.

Byrne, M. (2001). Critical incident technique as a qualitative research method. AORN Journal: The Official Voice of Perioperative Nursing, 74(4), 536-539..

Connor, J., \& Casswell, S. (2009). The burden of road trauma due to other people's drinking. Accident Analysis \& Prevention, 41(5), 1099-1103.

Darrow, C. J., Collins, C. L., Yard, E. E., \& Comstock, R. D. (2009). Epidemiology of severe injuries among United States high school athletes: 2005-2007. American Journal of Sports Medicine, 37(9), 1798-1805.

DeJoy, D. M. (1989). The optimism bias and traffic accident risk perception. Accident Analysis \& Prevention, 21(4), 333-340.

Douglass, C. B. (2007). From duty to desire: Emerging adulthood in Europe and its consequences. Child Development Perspectives, 1(2), 101-108.

European Association for Injury Prevention and Safety Promotion. (2014). Injuries in the European Union: Summary of injury statistics for the years 2010-2012. Amsterdam, The Netherlands: Author. 
International Journal of Child, Youth and Family Studies (2017) 8(1): 97-111

European Association for Injury Prevention and Safety Promotion. (2013). Injuries in the European Union: Report on injury statistics 2008-2010. Amsterdam, The Netherlands: Author.

Flanagan, C. (1954). The critical incident technique. Psychological Bulletin, 51, 327-358.

Graneheim, U. H., \& Lundman B. (2004). Qualitative content analysis in nursing research: Concepts, procedures and measures to achieve trustworthiness. Nurse Education Today, 24(2), 105-112.

Haddon, W., Jr. (1980). Advances in the epidemiology of injuries as a basis for public policy. Public Health Reports, 95(5), 411-421.

Hasselberg, M., Laflamme, L., \& Weitoft, G. R. (2001). Socioeconomic differences in road traffic injuries during childhood and youth: A closer look at different kinds of road user. Journal of Epidemiology \& Community Health, 55(12), 858-862.

Heinrich, H. W. (1931). Industrial Accident Prevention. New York, NY: McGraw-Hill.

Hensing, G. K., Sverker, A. M., \& Leijon, G. S. (2007). Experienced dilemmas of everyday life in chronic neuropathic pain patients--results from a critical incident study. Scandinavian Journal of Caring Sciences, 21(2), 147-154.

Iacovou, M. (2010) Leaving home: Independence, togetherness and income. Advances in Life Course Research, 15, 147-160.

Johnson, R. J., McCaul, K. D., \& Klein, W. M. (2002). Risk involvement and risk perception among adolescents and young adults. Journal of Behavioral Medicine, 25(1), 67-82.

Jones, S., Kirchsteiger, C., \& Bjerge, W. (1999). The importance of near-miss reporting to further improve safety performance. Journal of Loss Prevention in the Process Industries, 12(1), 59-67.

Koehoorn, M., Breslin, F. C., \& Xu, F. (2008). Investigating the longer-term health consequences of work-related injuries among youth. Journal of Adolescent Health, 43(5), 466-473.

Kontos, A. P. (2004). Perceived risk, risk taking, estimation of ability and injury among adolescent sport participants. Journal of Pediatric Psychology, 29, 447-455.

le Blanc, D., \& Wolff, F-C. (2006). Leaving home in Europe: The role of parents' and children's incomes. Review of Economics of the Household, 4, 53-73. doi:10.1007/s11150-005-6697-z

Mulye, T. P., Park, M. J., Nelson C. D., Adams, S. H., Irwin, C. E., Jr., \& Brindis, C. D. (2009). Trends in adolescent and young adult health in the United States. Journal of Adolescent Health, 45(1), 8-24. 
International Journal of Child, Youth and Family Studies (2017) 8(1): 97-111

Parsons, J. T., Siegel, A. W., \& Cousins, J. H. (1997). Late adolescent risk-taking: Effects of perceived benefits and perceived risks on behavioral intentions and behavioral change. Journal of Adolescence, 20(4), 381-392.

Peek-Asa, C., \& Zwerling, C. (2003). Role of environmental interventions in injury control and prevention. Epidemiologic Reviews, 25, 77-89

Reniers, R. L., Beavan, A., Keogan, L., Furneaux, A., Mayhew, S., \& Wood, S. J. (2017) Is it all in the reward? Peers influence risk-taking behavior in young adulthood. British Journal of Psychology, 108(2):276-295. doi:10.1111/bjop.12195

Runyan, C. W., \& Zakocs, R. C. (2000). Epidemiology and prevention of injuries among adolescent workers in the United States. Annual Review of Public Health, 21, 247-269.

Salminen, S. (2004). Have young workers more injuries than older ones? An international literature review. Journal of Safety Research, 35(5), 513-521.

Sjoberg, L. (2000). Factors in risk perception. Risk Analysis, 20(1), 1-11.

Slovic, P., Finucane, M. L., Peters, E., \& MacGregor, D. G. (2004). Risk as analysis and risk as feelings: Some thoughts about affect, reason, risk, and rationality. Risk Analysis, 24(2), 311-322.

Steffen, K., Myklebust, G., Olsen, O. E., Holme, I., \& Bahr, R. (2008). Preventing injuries in female youth football: A cluster-randomized controlled trial. Scandinavian Journal of Medicine \& Science in Sports, 18(5), 605-614.

Suvivou, P., Tossavainen, K., \& Kontula, O. (2007). The role of alcohol in a sexually motivated situation. Health Education, 108(2), 145-162.

Sverker, A., Hensing, G., \& Hallert C. (2005). 'Controlled by food' — lived experiences of coeliac disease. Journal of Human Nutrition and Dietetics, 18(3), 171-180.

Wagner, L. M., Capezuti, E., \& Ouslander, J. G. (2006). Reporting near-miss events in nursing homes. Nursing Outlook, 54(2), 85-93.

Walther, A. (2006). Regimes of youth transitions: Choice, flexibility and security in young people's experiences across different European contexts. Young: Nordic Journal of Youth Research, 14(2), 119-139.

Wegman, D. H., \& Davis, L. K. (1999). Protecting youth at work. American Journal of Industrial Medicine, 36(5), 579-583.

Wild, L. G., Flisher, A., Bhana, A., \& Lombard. C. (2004) Associations among adolescent risk behaviours and self-esteem in six domains. Journal of Child Psychology and Psychiatry, 45(8), 1454-1467. 
International Journal of Child, Youth and Family Studies (2017) 8(1): 97-111

WISQARS. (2010). Leading causes of death, fatal and non-fatal injury reports. Atlanta, GA: Centers for Disease Control and Prevention, National Center for Injury Prevention and Control, U.S. Department of Health \& Human Services. Retrieved August 23rd, 2010 from http://www.cdc.gov/injury/wisqars/

Wright, L., \& van der Schaaf, T. (2004). Accident versus near miss causation: A critical review of the literature, an empirical test in the UK railway domain, and their implications for other sectors. Journal of Hazardous Materials, 111(1-3), 105-110. 